\title{
The Treatment of Ectopic Pregnancy with Laparoscopy-Assisted Local Injection of Chemotherapeutic Agents
}

\author{
Ching-Hui Chen ${ }^{1}$, Peng-Hui Wang ${ }^{2}$, Li-Hsuan Chiu ${ }^{3}$ and Wei-Min Liu1 ${ }^{*}$ \\ ${ }^{1}$ Department of Obstetrics and Gynecology, Taipei Medical University \\ Hospital and Taipei Medical University, Taipei \\ ${ }^{2}$ Department of Obstetrics and Gynecology, Taipei Veterans General \\ Hospital and National Yang-Ming University, Taipei \\ ${ }^{3}$ Graduate Institute of Medical Sciences, Taipei Medical University, Taipei
}

Taiwan

\section{Introduction}

Laparoscopy-assisted local injection of chemotherapeutic agents is not yet considered as a standard treatment for ectopic pregnancy. Herein, we demonstrated cases of cesarean scar pregnancy and ovarian ectopic pregnancy successfully treated with trans-vaginal sonography-guided local injection of etoposide. Furthermore, we evaluated the efficacy of laparoscopic local injection of etoposide compared with methotrexate on tubal pregnancy treatment. With the aid of laparoscopic injection, local etoposide treatment offers a precise localization and minimally invasive approach to the management of ectopic pregnancies. Compared to the conventional way to treat ectopic pregnancy using methotrexate, local injection of etoposide is considered to be a high-success rate, low-risk, and less-limitation option for such types of ectopic pregnancies with careful selection of cases.

\section{Current opinion and therapeutic strategy on ectopic pregnancies}

Ectopic pregnancy is a complication of pregnancy in which the fetus implants outside the endometrial cavity, which ultimately ends in death of the fetus. It constitutes $1.6 \%$ of all pregnancies (Lurie, 1992). Most ectopic pregnancies are located in the fallopian tube, but the implantation can also occur in the cervix, ovaries, abdomen, and even cesarean scars. Ectopic pregnancy is usually not viable. If left untreated, half of ectopic pregnancies will resolve without treatment and presents as the tubal abortions. Ectopic pregnancies are considered as a dangerous health problem for women of childbearing age because of the internal bleeding as a common complication. In fact, maternal mortality is $0.14 \%$ in cases of ectopic pregnancy (Lurie, 1992; Te Linde, Rock, \& Thompson, 1997).

Within various forms of ectopic pregnancies, cesarean scar pregnancy is a rare form of ectopic implantation. The pathogenesis is thought to be a normal fertilization followed by implantation at the ecchymotic lesion site which is bulging from the uterine wall at the

${ }^{*}$ Corresponding Author 
cesarean scar. If a caesarean scar pregnancy continues developing to second or third trimesters, there might be risks of uterine rupture or catastrophic hemorrhage which may cause serious maternal morbidity and loss of fertility. Differential diagnosis and early diagnosis of such an ectopic pregnancy is now more feasible because of the use of highresolution transvaginal sonography and the availability of sensitive $\beta$-hCG assay.

Primary ovarian pregnancy is also considered as an uncommon form of ectopic implantation and represents $0.5 \%-3 \%$ of all ectopic pregnancies. The pathogenic mechanism is thought to be fertilization occurring outside the tube, followed by implantation within the ovary. Differential diagnosis of an ovarian pregnancy from a tubal pregnancy has been a challenge in the past. However, due to the improvement of high-resolution transvaginal sonography and the availability of sensitive $\beta$-hCG assay, an early diagnosis of an ovarian pregnancy is now more feasible.

Once diagnosed, the conventional treatment of ectopic pregnancy is surgical approach. The traditional method for management of a cesarean scar pregnancy is surgical removal of the ectopic pregnancy (Arslan, et al., 2005; C. B. Wang \& Tseng, 2006; Y. L. Wang, Su, \& Chen, 2006). There have been few reports showing that cesarean scar pregnancies were successfully treated by local injection of methotrexate (Hwu, Hsu, \& Yang, 2005; Ravhon, Ben-Chetrit, Rabinowitz, Neuman, \& Beller, 1997). Similarly, the traditional management mean for ovarian pregnancy is surgical removal of the ectopic site, either by ipsilateral oophorectomy or wedge resection by laparotomy or laparoscopy(Yen \& Wang, 2004). There has been sporadic case reports showing that ovarian pregnancy was successfully treated by systemic methotrexate injection (Chelmow, Gates, \& Penzias, 1994; Field \& Faraj, 2005; Habbu \& Read, 2006).

Methotrexate is not yet a first-line treatment for ovarian pregnancy or cesarean scar pregnancy even in candidates who meet the criteria for medical treatment (Bagga, Suri, Verma, Chopra, \& Kalra, 2006; Medical treatment of ectopic pregnancy," 2006). However, the use of systemic methotrexate treatment has considered being an option to preserve potential fertility in ectopic pregnancy patients (Hung, Jeng, Yang, Wang, \& Lan, 1996; Marcovici, Rosenzweig, Brill, Khan, \& Scommegna, 1994; Timor-Tritsch, et al., 1994). Several risk factors have to be evaluated while systemic methotrexate is indicated for the treatment of ectopic pregnancy. The patient should be hemodynamically stable, have no severe contraindications to methotrexate. Furthermore, the size of the gestation sac should not exceed $3 \mathrm{~cm}$ under ultrasound measurement, and the serum $\beta$-hCG level should not exceed $2000 \mathrm{mIU} / \mathrm{mL}$. In cases of tubal ectopic pregnancy, the presence of an embryonic cardiac activity was generally considered to be a contraindication to methotrexate therapy (Ory, 1992). Ushakov et al. reported that the side effects of systemic methotrexate treatment occurred $15 \%$ of the time, which include bone marrow depression, stomatitis, anorexia, nausea, vomiting, and diarrhea (Floridon \& Thomsen, 1994; Ushakov, Elchalal, Aceman, \& Schenker, 1997). These contraindications and side effects have become the limitations of systemic treatment of methotrexate on ectopic pregnancy.

AS a result, considering the highly vascularized tissues involved in the surgical procedure and the contraindications of systemic therapy, local injection of the chemotherapeutic agents is then suggested. There have been few reports showing that ectopic pregnancies were successfully treated by local injection of methotrexate or etoposide (C. H. Chen, Wang, \& Liu, 2009; Hwu, et al., 2005; Juan, Wang, Chen, Ma, \& Liu, 2008; Ravhon, et al., 1997). With laparoscopic local injection, the chemotherapeutic agent such as methotrexate or etoposide could be precisely injected into the ectopic implantation. These procedures lead to a significant decline in side effects and contribute to the preservation of the patients' reproductive potential. However, comparing to methotrexate, etoposide is not yet a widely used treatment for ectopic 
pregnancy, and there are still no criteria established. Even in cases of all kinds of ectopic pregnancy, the uses of etoposide were reported in less than ten cases since 1990 (C. L. Chen, Wang, Chiu, Yang, \& Hung, 2002; Juan, et al., 2008; Mantalenakis, et al., 1995; Seki, Kuromaki, Takeda, \& Kinoshita, 1997; Takashima, et al., 1995). Herein we demonstrated various cases including ovarian, CS scar, and tubal pregnancies successfully treated by laparoscopic local injection of etoposide with trans-vaginal sonography -assisted localization. Furthermore, since etoposide and methotrexate have been applied locally to treat ectopic pregnancy, we evaluated the clinical efficacies of local treatment of these two chemotherapeutic agents.

\section{Cases: The treatment of cesarean scar and ovarian pregnancies with laparoscopy-assisted local injection of etoposide}

Case I: A 37 year-old-female, gravida 5, para 2 (cesarean section twice), abortion 2, had presented with a 8-week history of gestational amenorrhea. She accidentally found herself pregnancy and asked for an elective abortion in a local clinic. Her general condition was fair. She was considered intra-uterine pregnancy at local clinic and uterine curettage had been performed 3 times since she kept suffering from vaginal bleeding after first curettage. She came to our hospital for second opinion due to persistent vaginal bleeding. trans-vaginal sonography revealed an empty uterus and suggested an ectopic sac of $1.9 \times 1.7 \mathrm{~cm}$ in diameter between anterior wall of uterus and bladder on previous cesarean scar. $\beta$-hCG level was measured at $572.2 \mathrm{mIU} / \mathrm{mL}$. Based on these findings, a cesarean pregnancy was suspected. A laparoscopy was then performed while an ecchymotic lesion $(2 \mathrm{~cm})$ found bulging from the uterine wall at the previous cesarean scar area. The two fallopian tubes and two ovaries were intact and normal. Confirmed with trans-vaginal sonography, the mass was indicated

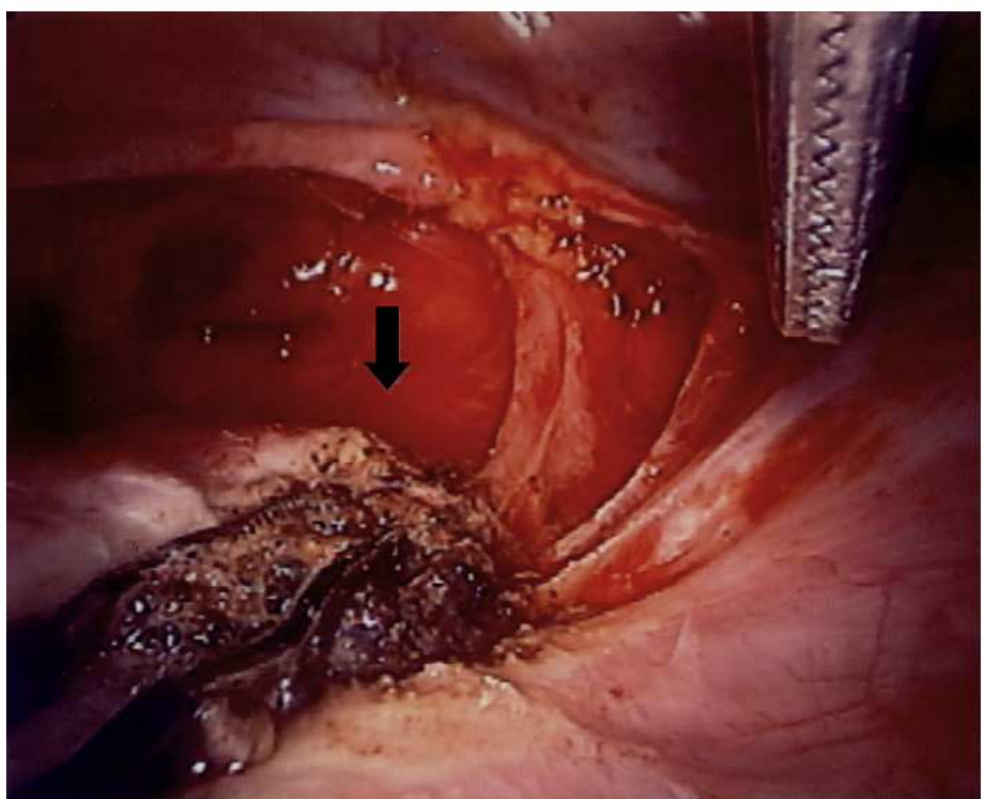

Fig. 1. Chemotherapeutic agent was injected into the ectopic sac laparoscopically, followed by bipolar electrocoagulation (black arrow). 
a cesarean scar pregnancy. With the guidance of trans-vaginal sonography to precisely estimate the depth of the puncture site to the gestational sac, $100 \mathrm{mg}$ of etoposide was directly injected into the ectopic sac by laparoscopy (Figure 1). The puncture site was immediately sealed by bipolar electro-coagulation. The patient was followed up with serial trans-vaginal sonography and $\beta$-hCG level monitoring. The trans-vaginal sonography showed a progressive shrinkage of the mass, and the $\beta$-hCG levels declined continuously to $28.1 \mathrm{mIU} / \mathrm{mL} 9$ days after the surgery, and $5.0 \mathrm{mIU} / \mathrm{mL} 17$ days later. The patient experienced normal menstruation 45 days after the procedure.

Case II: A 33-year-old woman, gravida 1, para 0, had presented with a 7-week history of gestational amenorrhea and lower abdominal discomfort. Her general condition was fair. The serum b-hCG level was measured at 2,765 mIU/mL. The trans-vaginal sonography revealed an empty uterus and suggested an ectopic sac of 4.3 by $2.8 \mathrm{~cm}$ in diameter in the right ovarian region. The fluid in the Douglas pouch measured $2.0 \times 1.8 \mathrm{~cm}$ in diameter. Based on these findings, an ovarian pregnancy was suspected. A laparoscopy was then performed. One hundred milliliters of bloody fluid was collected from the cul-de-sac. The two fallopian tubes were intact, and the uterus and left ovary were normal. A 4-cm diameter bluish and hemorrhagic mass on the right ovary indicated the possibility of an ovarian pregnancy. Punch with aspiration and direct injection of $100 \mathrm{mg}$ of etoposide into the ectopic sac (Figure 2) was performed and the fluid aspirated from the hemorrhagic sac seen

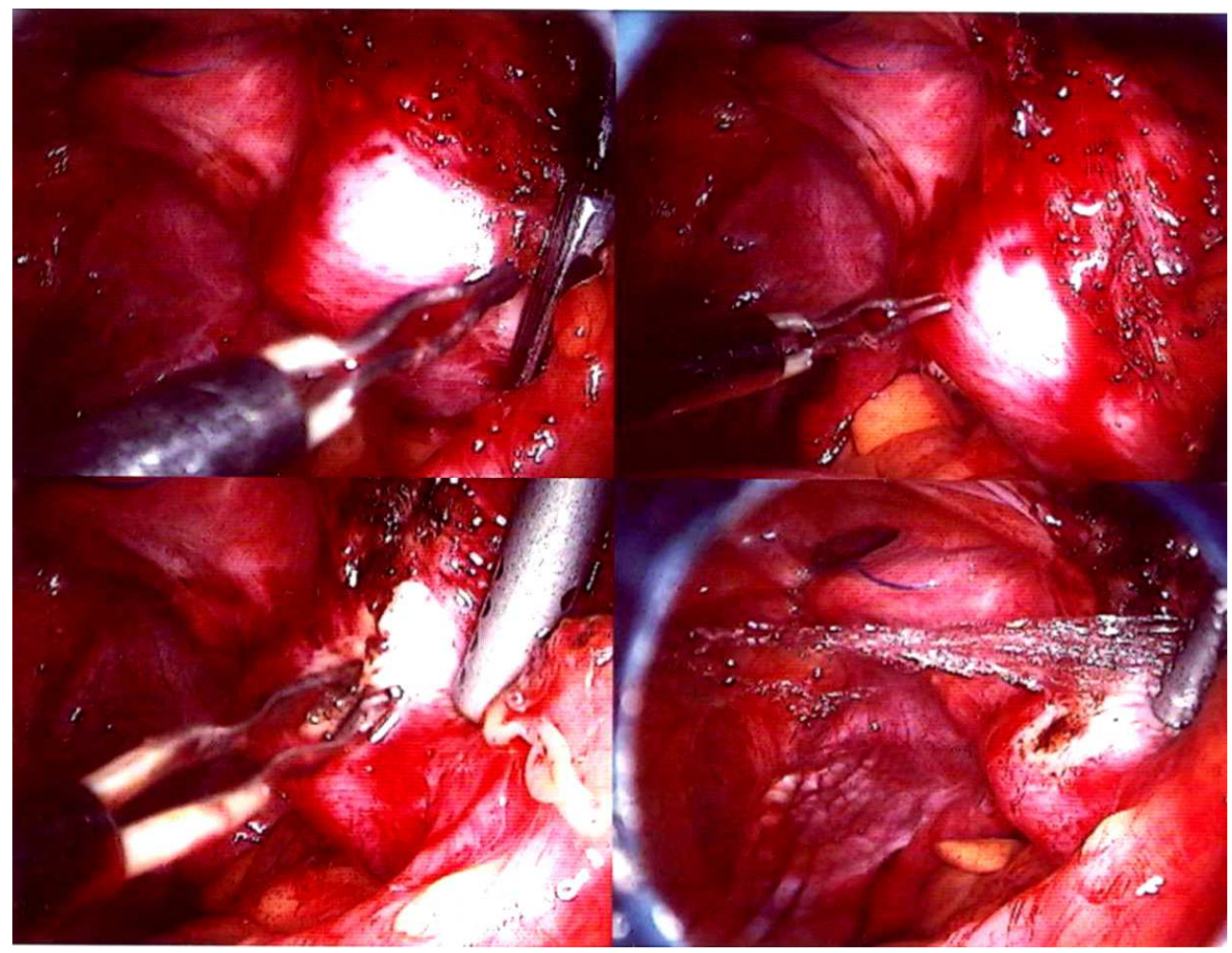

Fig. 2. After local injection of the chemotherapeutic agent, bipolar electro-coagulation was used to seal the puncture site. 
at laparoscopy was sent for pathologic examination, which showed scant chorionic villi and granulosa cells (GC) in support of the diagnosis of ovarian pregnancy. The patient was followed up with serial trans-vaginal sonography and checking of b-hCG levels. The b-hCG levels declined continuously to $37.34 \mathrm{mIU} / \mathrm{mL} 8$ days after surgery and $6.01 \mathrm{mIU} / \mathrm{mL} 1$ week later. The patient menstruated 25 days after the procedure.

The traditional treatments for ectopic pregnancies are considered more invasive procedures. Therefore, how to select one of the less invasive procedures to diagnose and treat this rare ectopic pregnancy is important. For example, in case I, a deeply implanted cesarean scar pregnancy was growing towards the abdominal cavity and bladder, thus we choose laparoscopy as a primary mean to approach the cesarean scar pregnancy (Vial, Petignat, \& Hohlfeld, 2000; C. J. Wang, et al., 2006). Trans-vaginal sonography-guided local injection not only offers a precise localization of the injection site, but also offered a minimally invasive procedure for the case. Furthermore, local injection of etoposide bypasses the systemic side effects of the drug. Taken together, trans-vaginal sonography-guided laparoscopic local injection of etoposide for such cases are suggested.

\section{The comparison of etoposide and methotrexate efficacies on tubal pregnancy treatment}

Etoposide, an antineoplastic agent, can produce cytotoxic effects by damaging DNA, thereby inhibiting or altering DNA synthesis. The drug appears to be cell-cycle dependent and cyclephase specific, inducing G2 phase arrest and killing cells in the G2 and late S phases. In 2002, Chen et al. successfully used a ultrasound-guided direct injection of etoposide to treat an interstitial pregnancy (C. L. Chen, et al., 2002). Based on the finding that etoposide was more effective and had fewer side effects in the management of low-risk gestational trophoblastic tumor, compared to methotrexate treatment (Matsui, et al., 2005), direct injection of etoposide for ectopic pregnancy is considered. Local administration of methotrexate was described in several cases (Hung, et al., 1996; Monteagudo, Minior, Stephenson, Monda, \& Timor-Tritsch, 2005; Timor-Tritsch, et al., 1994). On the other aspect, the use of etoposide in ectopic pregnancy is relatively new. The standardized protocol is not yet available, although there were few cases used ultrasound-guided direct injection of etoposide to treat ectopic pregnancy (C. H. Chen, et al., 2009; C. L. Chen, et al., 2002; Juan, et al., 2008).

From 1993 through 2009, 28 patients of tubal pregnancy received local injection of methotrexate or etoposide were documented. In all cases, age, body weight, hemoglobin level and the operation time were recorded. The gestational age, cardiac activity of the conceptus, $\beta$-hCG levels before and after the treatment, and the occurrence and outcomes of subsequent pregnancies were evaluated. Among the enrolled patients, methotrexate has been administered locally to 11 patients and etoposide to 17 patients. In group (I), $50 \mathrm{mg}$ of etoposide was injected into the ectopic sites by laparoscopy. In group (II), $50 \mathrm{mg}$ of methotrexate was applied. All patients were followed up with serial $\beta$-hCG level monitoring. None of the patients had significant side effects of systemic treatment of the agents. More than $50 \%$ of the patients had a gestational size of greater than $30 \mathrm{~mm}$.

The administration of methotrexate locally was chosen to avoid the adverse effect of systemic administration of methotrexate. Hung et al. observed that methotrexate alone or combined with procedures such as curettage or cervical tamponade is effective in ectopic pregnancies of up to 12 weeks (Hung, et al., 1996). In this survey, the median (range) of the time it took to decline to the non-pregnant $\beta$-hCG level (undetectable or below $5 \mathrm{mIU} / \mathrm{mL}$ ) of methotrexate injection group was longer than the etoposide injection group, though not significant difference is observed (Table 1). 


\begin{tabular}{|c|c|c|c|}
\hline & $\begin{array}{c}\text { Etoposide treatment } \\
(\mathrm{n}=11) \\
\text { Median (range) }\end{array}$ & $\begin{array}{c}\text { Methotrexate treatment } \\
\qquad(\mathrm{n}=17) \\
\text { Median (range) }\end{array}$ & $\begin{array}{c}\mathbf{P} \\
\text { Value }\end{array}$ \\
\hline Age (years) & $34(26 \sim 37)$ & $31(22 \sim 38)$ & - \\
\hline Body weight (kg) & $52.3(47.4 \sim 62.1)$ & $49.7(45 \sim 58)$ & - \\
\hline Basal Hgb (g/dL) & $11.1(9.7 \sim 12.8)$ & $10.6(9.3-13.1)$ & - \\
\hline$\beta-\mathbf{h C G}(\mathbf{m I U} / \mathbf{m L})$ & $2081(430.1 \sim 55225)$ & $7926(250 \sim 27356)$ & 0.50 \\
\hline Time of $\beta$-hCG level declined to below $5 \mathrm{mIU} / \mathrm{mL}$ (days) & $19(7 \sim 90)$ & $37(12 \sim 98)$ & 0.28 \\
\hline Time of involution of gestational sac (days) & 27 (18 116) & $44(19 \sim 134)$ & 0.26 \\
\hline
\end{tabular}

Table 1. Baseline characteristics of the enrolled women

There is still no consensus about the most appropriate treatment for ectopic pregnancy. Therefore, large prospective randomized trials are still needed to establish common selection criteria, dosage, and length of follow up of the therapies. Furthermore, to increase the success rate, experiences in invasive ultrasound-guided procedures is indeed crucial for the success of this treatment option, but careful selection of patients and their compliance is also important. In this study, local injection of $50 \mathrm{mg}$ etoposide to treat ectopic pregnancy was evaluated and compared with local injection of methotrexate. In women who desire future pregnancy, these two types of conservative treatment may be an acceptable and promising alternative in the management of ectopic pregnancy. Taken together, a local injection of etoposide might be a good choice for ectopic pregnancy.

\section{Summary}

The advances in ultrasound equipment and easy access to quantitative $\beta$-hCG have made the diagnosis of early ectopic pregnancies possible. The efforts to improve the management of ectopic pregnancy have also stimulated many investigators to design new approaches to treat early ectopic pregnancy. This enables successful application of conservative therapies such as local treatment of chemotherapeutic agents such as etoposide or methotrexate. Not like methotrexate, etoposide is not yet considered as a standard treatment for ectopic pregnancy while there are still no criteria established. As compared to local methotrexate treatment, local etoposide treatment has the advantages of better efficacy to treat patients with higher $\beta$-hCG level. With the aid of laparoscopic injection, local treatment of etoposide is considered as a precise localization and the minimally invasive option to the management of ectopic pregnancy.

\section{Acknowledgement}

Part of the contents and research materials in this chapter were extracted from our previous works in Fertility and Sterility. We are giving full acknowledgment of the original publication of the article. Changes may have been made to this work since it was extended and re-edited to a book-length form.

\section{References}

Arslan, M., Pata, O., Dilek, T. U., Aktas, A., Aban, M., \& Dilek, S. (2005). Treatment of viable cesarean scar ectopic pregnancy with suction curettage. Int J Gynaecol Obstet, 89(2), 163-166. 
Bagga, R., Suri, V., Verma, P., Chopra, S., \& Kalra, J. (2006). Failed medical management in ovarian pregnancy despite favorable prognostic factors--a case report. MedGenMed, $8(2), 35$.

Chelmow, D., Gates, E., \& Penzias, A. S. (1994). Laparoscopic diagnosis and methotrexate treatment of an ovarian pregnancy: a case report. Fertil Steril, 62(4), 879-881.

Chen, C. H., Wang, P. H., \& Liu, W. M. (2009). Successful treatment of cesarean scar pregnancy using laparoscopically assisted local injection of etoposide with transvaginal ultrasound guidance. Fertil Steril, 92(5), 1747 e1749-1711.

Chen, C. L., Wang, P. H., Chiu, L. M., Yang, M. L., \& Hung, J. H. (2002). Successful conservative treatment for advanced interstitial pregnancy. A case report. J Reprod Med, 47(5), 424-426.

Field, S. M., \& Faraj, R. (2005). Ovarian pregnancy in the wall of corpus luteum. J Obstet Gynaecol, 25(6), 615-616.

Floridon, C., \& Thomsen, S. G. (1994). Methotrexate treatment of ectopic pregnancy. Acta Obstet Gynecol Scand, 73(10), 746-752.

Habbu, J., \& Read, M. D. (2006). Ovarian pregnancy successfully treated with methotrexate. J Obstet Gynaecol, 26(6), 587-588.

Hung, T. H., Jeng, C. J., Yang, Y. C., Wang, K. G., \& Lan, C. C. (1996). Treatment of cervical pregnancy with methotrexate. Int J Gynaecol Obstet, 53(3), 243-247.

Hwu, Y. M., Hsu, C. Y., \& Yang, H. Y. (2005). Conservative treatment of caesarean scar pregnancy with transvaginal needle aspiration of the embryo. BJOG, 112(6), 841842.

Juan, Y. C., Wang, P. H., Chen, C. H., Ma, P. C., \& Liu, W. M. (2008). Successful treatment of ovarian pregnancy with laparoscopy-assisted local injection of etoposide. Fertil Steril, 90(4), 1200 e1201-1202.

Lurie, S. (1992). The history of the diagnosis and treatment of ectopic pregnancy: a medical adventure. Eur J Obstet Gynecol Reprod Biol, 43(1), 1-7.

Mantalenakis, S., Tsalikis, T., Grimbizis, G., Aktsalis, A., Mamopoulos, M., \& Farmakides, G. (1995). Successful pregnancy after treatment of cervical pregnancy with methotrexate and curettage. A case report. J Reprod Med, 40(5), 409-414.

Marcovici, I., Rosenzweig, B. A., Brill, A. I., Khan, M., \& Scommegna, A. (1994). Cervical pregnancy: case reports and a current literature review. Obstet Gynecol Surv, 49(1), 49-55.

Matsui, H., Suzuka, K., Yamazawa, K., Tanaka, N., Mitsuhashi, A., Seki, K., et al. (2005). Relapse rate of patients with low-risk gestational trophoblastic tumor initially treated with single-agent chemotherapy. Gynecol Oncol, 96(3), 616-620.

Medical treatment of ectopic pregnancy. (2006). Fertil Steril, 86(5 Suppl 1), S96-102.

Monteagudo, A., Minior, V. K., Stephenson, C., Monda, S., \& Timor-Tritsch, I. E. (2005). Non-surgical management of live ectopic pregnancy with ultrasound-guided local injection: a case series. Ultrasound Obstet Gynecol, 25(3), 282-288.

Ory, S. J. (1992). New options for diagnosis and treatment of ectopic pregnancy. JAMA, 267(4), 534-537.

Ravhon, A., Ben-Chetrit, A., Rabinowitz, R., Neuman, M., \& Beller, U. (1997). Successful methotrexate treatment of a viable pregnancy within a thin uterine scar. Br J Obstet Gynaecol, 104(5), 628-629. 
Seki, H., Kuromaki, K., Takeda, S., \& Kinoshita, K. (1997). Ovarian pregnancy diagnosed in the third trimester: a case report. J Obstet Gynaecol Res, 23(6), 543-546.

Takashima, M., Yamasaki, M., Fujita, I., Ohashi, M., Matsuo, H., Mochizuki, M., et al. (1995). Enhanced magnetic resonance imaging in monitoring of conservative treatment of cervical pregnancy. J Obstet Gynaecol, 21(6), 545-550.

Te Linde, R. W., Rock, J. A., \& Thompson, J. D. (1997). Te Linde's operative gynecology (8th ed.). Philadelphia: Lippincott-Raven.

Timor-Tritsch, I. E., Monteagudo, A., Mandeville, E. O., Peisner, D. B., Anaya, G. P., \& Pirrone, E. C. (1994). Successful management of viable cervical pregnancy by local injection of methotrexate guided by transvaginal ultrasonography. Am J Obstet Gynecol, 170(3), 737-739.

Ushakov, F. B., Elchalal, U., Aceman, P. J., \& Schenker, J. G. (1997). Cervical pregnancy: past and future. Obstet Gynecol Surv, 52(1), 45-59.

Vial, Y., Petignat, P., \& Hohlfeld, P. (2000). Pregnancy in a cesarean scar. Ultrasound Obstet Gynecol, 16(6), 592-593.

Wang, C. B., \& Tseng, C. J. (2006). Primary evacuation therapy for Cesarean scar pregnancy: three new cases and review. Ultrasound Obstet Gynecol, 27(2), 222-226.

Wang, C. J., Chao, A. S., Yuen, L. T., Wang, C. W., Soong, Y. K., \& Lee, C. L. (2006). Endoscopic management of cesarean scar pregnancy. Fertil Steril, 85(2), 494 e491494.

Wang, Y. L., Su, T. H., \& Chen, H. S. (2006). Operative laparoscopy for unruptured ectopic pregnancy in a caesarean scar. BJOG, 113(9), 1035-1038.

Yen, M. S., \& Wang, P. H. (2004). Primary ovarian ectopic pregnancy. J Am Assoc Gynecol Laparosc, 11(3), 287-288. 


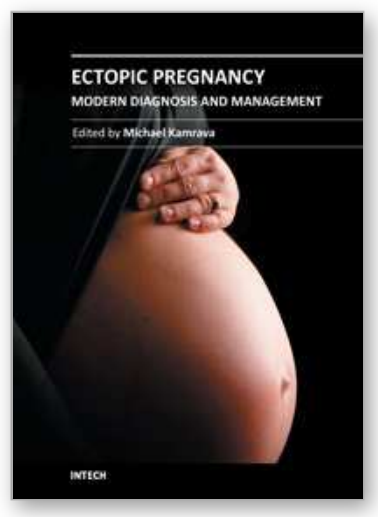

\author{
Ectopic Pregnancy - Modern Diagnosis and Management \\ Edited by Dr. Michael Kamrava
}

ISBN 978-953-307-648-5

Hard cover, 248 pages

Publisher InTech

Published online 26, October, 2011

Published in print edition October, 2011

Ectopic pregnancy is the second major cause of maternal mortality in the United States and a leading cause of maternal morbidity and mortality in the world. This book contains the practical methods to early diagnosis of various forms of ectopic pregnancies and their modern management. Ectopic Pregnancy - Modern Diagnosis and Management is a comprehensive book which guides the reader through all features of ectopic pregnancy, both practical and academic, covering all aspects of diagnosis and management of ectopic pregnancy in a clear, concise, and practical fashion. The book is organized so that it can either be read cover to cover for a comprehensive tutorial or be kept desk side as a reference to the ectopic pregnancies. Each chapter introduces a number of related ectopic pregnancy and its diagnosis, treatment and co-morbidities supported by examples. Included chapters bring together valuable materials in the form of extended clinical knowledge from practice to clinic features.

\title{
How to reference
}

In order to correctly reference this scholarly work, feel free to copy and paste the following:

Ching-Hui Chen, Peng-Hui Wang, Li-Hsuan Chiu and Wei-Min Liu (2011). The Treatment of Ectopic Pregnancy with Laparoscopy-Assisted Local Injection of Chemotherapeutic Agents, Ectopic Pregnancy Modern Diagnosis and Management, Dr. Michael Kamrava (Ed.), ISBN: 978-953-307-648-5, InTech, Available from: http://www.intechopen.com/books/ectopic-pregnancy-modern-diagnosis-and-management/thetreatment-of-ectopic-pregnancy-with-laparoscopy-assisted-local-injection-of-chemotherapeutic-age

\section{INTECH}

open science | open minds

\section{InTech Europe}

University Campus STeP Ri

Slavka Krautzeka 83/A

51000 Rijeka, Croatia

Phone: +385 (51) 770447

Fax: +385 (51) 686166

www.intechopen.com

\section{InTech China}

Unit 405, Office Block, Hotel Equatorial Shanghai

No.65, Yan An Road (West), Shanghai, 200040, China

中国上海市延安西路65号上海国际贵都大饭店办公楼405单元

Phone: +86-21-62489820

Fax: $+86-21-62489821$ 
(C) 2011 The Author(s). Licensee IntechOpen. This is an open access article distributed under the terms of the Creative Commons Attribution 3.0 License, which permits unrestricted use, distribution, and reproduction in any medium, provided the original work is properly cited. 